\title{
UM OLHAR SOBRE A FORMAÇÃO CONTINUADA DE PROFESSORES NA REDE MUNICIPAL DE RECIFE/PE
}

\section{A LOOK AT CONTINUED TEACHER TRAINING AT THE RECIFE/PE MUNICIPAL NETWORK}

\author{
Mario Marcos Lopes ${ }^{1}$, Luiza Maria Rodrigues Costa²
}

Submetido em: 31/07/2019

Correções requeridas em: $28 / 04 / 2020$

Aprovado em: $14 / 09 / 2020$

\section{RESUMO}

O presente estudo investiga o processo de formação continuada na Rede Municipal de Recife. Teve como objetivo geral, verificar os impactos da formação continuada de professores na Rede Municipal de Ensino de Recife. Para alcançar os objetivos propostos essa investigação adotou uma perspectiva qualitativa. A metodologia consistiu no acompanhamento de formações continuadas ofertadas, aos professores de $4^{\circ} \mathrm{s}$ e $5^{\circ} \mathrm{s}$ anos, pela Rede Municipal de Ensino de Recife ao longo de 5 meses de formação. A primeira parte da pesquisa consistiu na análise documental do Plano de Ação/2018 em que havia a programação anual das formações. Em seguida foram analisadas as respostas dadas pelos docentes em um formulário avaliativo e os relatórios feitos pelos formadores responsáveis por esse grupo de professores. Os resultados evidenciaram que o modelo de organização das formações possibilitou um aprofundamento de temáticas trabalhadas por semestres, apesar de haver algumas limitações. Nas avaliações, os docentes apontaram que nem sempre as formações auxiliavam-nos em sua prática, já que os temas propostos no primeiro semestre só seriam trabalhados pelos docentes no segundo semestre, segundo a matriz curricular da referida rede. Os momentos formativos, de uma forma geral, foram bem avaliados pelos professores, que percebiam, em grande parte, a articulação entre teoria e prática, bem como reconheciam o espaço, durante a formação, para o compartilhar de experiências docentes. Conclui-se, então, que o momento de formação continuada é importante para o fortalecimento da identidade docente, promovendo uma ressignificação da ação pedagógica e o aumento do protagonismo dos professores.

PALAVRAS-CHAVE: Formação docente. Formação continuada. Identidade docente.

\footnotetext{
${ }^{1}$ Mestre em Desenvolvimento Regional e Meio Ambiente pela Universidade de Araraquara (2011). Especialista em: Tecnologias e Educação a Distância (2016) pelo Centro Universitário Barão de Mauá, Orientação Educacional (2018), Educação Ambiental e Desenvolvimento Sustentável (2016), Gestão Estratégica de Pessoas (2015), Gestão Escolar (2013) e Didática e Tendências Pedagógicas (2011) pela Faculdade de Educação São Luís e Aperfeiçoamento em Educação Ambiental pela Universidade Federal de São João del Rei - MG (2010). Graduação em Ciências Biológicas pelo Centro Universitário Barão de Mauá (2008) e Pedagogia (2016) pela Fatece. Docente da pós-graduação modalidade EaD do Centro Universitário Barão de Mauá nas disciplinas de: Tecnologia Educacional na Gestão do Conhecimento: Educação Continuada e Evolução Profissional; Metodologia da Pesquisa Científica; Planejamento, avaliação e metodologias em educação ambiental e orienta trabalhos de conclusão. Atua como Tutor no Curso de Especialização em Computação aplicada à Educação Básica oferecido pela Universidade Federal de São João del-Rei (UFSJ). É professor-tutor e orientador de TCC dos Cursos de Especialização da Faculdade de Educação São Luís, além de ministrar aulas nas disciplinas de Gestão Ambiental e Metodologia do Ensino de Ciências. Atua como Professor Coordenador (Secretaria de Estado da Educação) - Diretoria Regional de Ensino de Ribeirão Preto. Correio eletrônico: mmarlopes@ig.com.br

2 Centro Universitário Barão de Mauá. Correio eletrônico: luizamrcosta@gmail.com
} 


\begin{abstract}
The purpose of this study was to investigate the process of continuous training in the Municipal Network of Recife. The main objective of this study was to verify the impacts of continuing teacher education on the Recife Teaching Municipal Network and as specific objectives: a) to analyze the organization of continuing education; b) to verify the repercussions of the formations in the space of the classrooms. To reach the proposed objectives, this research adopted a qualitative perspective. The methodology consisted in the follow-up of continuous training offered to the teachers of the 4th and 5th years, by the Municipal Network of Teaching of Recife during 5 months of training. The first part of the research consisted of the documentary analysis of the Plan of Action / 2018 in which there was the annual training program. Then the answers given by the teachers in an evaluation form and the reports made by the teachers responsible for this group of teachers were analyzed. The results showed that the training organization model allowed a deepening of the themes worked by semesters, although there are some limitations. In the evaluations, the teachers pointed out that the training did not always help them in their practice, since the subjects of the first semester training only needed to be worked by the teachers in the second semester, according to the curricular matrix of said network. The formative moments, in a general way, were well evaluated by the teachers, who perceived, in great part, the articulation between theory and practice, as well as recognized the space, during the formation, for the sharing of teaching experiences. It is concluded, then, that the moment of continuous formation is important for the strengthening of the teaching identity, promoting a re-signification of the pedagogical action and the increase of the protagonism of the teachers.
\end{abstract}

KEYWORDS: Teacher training. Continuing education. Teacher identity. 


\section{INTRODUÇÃO}

$\mathrm{Na}$ contemporaneidade tem-se observado que, na esfera da educação mundial, o Brasil tem ficado muito abaixo do esperado. Empenhados em desvendar esse problema, alguns estudos têm sido realizados no sentido de não apenas expor os motivos; mas, sobretudo, descobrir os caminhos que conduzam a resultados melhores no Sistema Educacional Brasileiro.

Em 2007, no Brasil, foi criado o IDEB - Índice de Desenvolvimento da Educação Básica, com o objetivo de medir a qualidade do aprendizado nacional a partir de avaliações das disciplinas de Língua Portuguesa e Matemática nos $5^{\circ} \mathrm{s}$ e $9^{\circ} \mathrm{s}$ anos. Os resultados obtidos evidenciam que muitas crianças não conseguem consolidar o processo de alfabetização, nem construir conceitos matemáticos básicos nos três anos iniciais de escolarização, acarretando numa defasagem perceptível e impactante ao final do Ensino Fundamental.

Diversos estudos (ALVES, SILVA, 2013; PIMENTA, 2002; LIBÂNEO, 2012, ROMANOWSKY, 2011; AZEVEDO, 1997; NÓVOA, 1995) na área educacional já tem apresentado a formação docente como caminho para melhorar a aprendizagem. Desse modo os presentes autores, enquanto formadores de professores, buscam levar à compreensão da importância da formação inicial e continuada dos docentes, não apenas para o fazer pedagógico, mas também para a construção da cultura profissional, pois, como afirma Nóvoa (1995, p. 24) “[...] a formação de professores pode desempenhar um papel importante na configuração de uma nova personalidade docente".

Em específico, a Rede de Ensino de Recife vem apresentando melhoras significativas em relação aos marcadores de desempenho da educação (índice do IDEB), mas ainda permanece abaixo do esperado. Esse fato nos motivou a realizar um estudo sobre o processo de formação continuada de professores da Rede de Ensino de Recife. O objetivo geral da pesquisa foi verificar os impactos da formação continuada de professores na Rede Municipal de Ensino de Recife e os objetivos específicos concentraram-se em: a) analisar o modo de organização da formação continuada; b) verificar as repercussões das formações no espaço das salas de aula.

Pimenta (2002) constatou que o crescimento quantitativo dos sistemas de ensino não tem correspondido ao crescimento formativo (qualitativo) adequado às exigências da população. Isso leva a atentar para uma nova construção na identidade profissional, já que essas modernas demandas educacionais exigem uma nova identidade profissional do (a) docente. Identidade que deve ser construída ao longo da sua trajetória profissional através das suas experiências e história pessoal, dentro de um coletivo favorecido pelos momentos de formação.

Buscando atender aos objetivos propostos, adotou-se uma abordagem qualitativa da pesquisa, realizando, a princípio, uma análise documental de forma a compreender como foi estruturada a formação continuada dos professores de Recife ao longo do ano de 2018. Em virtude do grande número de formações oferecida a diferentes públicos, firmou-se o olhar sobre as formações de professores de $4^{\circ} \mathrm{s}$ e $5^{\circ} \mathrm{s}$ anos ao longo de 5 meses de trabalho e para atender aos objetivos formulados usando como instrumentos de coleta de dados uma ficha avaliativa preenchida por cada docente ao final das formações e a um relatório de observações feitas pela equipe de formadores da Escola de Formação de Professores Professor Paulo Freire.

\section{FORMAÇÃO E SABERES DOCENTES}

\section{A importância da formação inicial e continuada de professores}

O professor é um dos profissionais que mais sofre influências do ambiente social, tendo que atender às demandas de uma sociedade em constante mudança. A globalização, as diferenças sociais, a presença de novas tecnologias, causam impacto na sociedade e na educação escolar (AZEVEDO, 1997). Desse modo, ele acaba tornando-se um profissional que precisa atualizarse permanentemente, para que consiga contribuir para a aprendizagem efetiva dos seus alunos.

Em virtude dessa volatilidade é preciso que o docente esteja atento para conduzir seu fazer pedagógico, promovendo a formação de seus alunos, ajudando-os a desenvolver suas capacidades cognitivas e orientando-os para a construção de uma sociedade mais justa e democrática.

Segundo Libâneo (2012, p. 13), "o papel da escola é o de prover aos alunos a apropriação da cultura e da ciência acumulados historicamente, como condição para 
o seu desenvolvimento mental e de torná-los aptos à reorganização crítica dessa cultura". Considerando esse papel da escola, é preciso reconhecer o importante papel do docente, posto que é ele quem vai ser responsável por planejar e orientar situações didáticas que promovam essa apropriação da cultura, do conhecimento histórico e científico, mas também que levem os alunos a tornaremse sujeitos críticos dessa mesma cultura.

Tendo os professores demandas tão significativas, é primordial que se pense nos processos formativos que os permita atuar de forma mais plena, considerando o papel desenvolvido por esse profissional na sociedade.

Os processos formativos, dessa forma, são extremamente relevantes, seja a formação inicial, seja a formação continuada.

De acordo com Romanowski (2011), desde a década de 1990 os sistemas de ensino começaram a pensar na formação de professores poderia promover melhoria nos processos de ensino e assim houve definição de políticas de formação de professores que previam elevação da exigência para os cursos de formação inicial do professor, bem como a ampliação da formação continuada. Em nossa Lei de Diretrizes e Bases da Educação Nacional - LDB, Lei nº 9.394/96 (BRASIL, 1996), houve a determinação da formação dos docentes que atuariam na educação básica seria em nível superior, em curso de licenciatura, apesar de admitir a formação em nível médio, na modalidade Normal. Houve então um processo de expansão dos cursos de licenciatura e abertura de novas instituições de ensino superior.

Mesmo havendo essa expansão ainda há professores que não são licenciados na disciplina onde atuam. Alves e Silva (2013) apontaram em sua pesquisa que apenas parte dos professores que atuavam, em 2009, nos anos finais do ensino fundamental possuíam a formação adequada. Segundo Gatti (2014), pesquisas mostram que há uma ausência de política nacional específica, articulada, voltada para a qualificação da formação inicial de professores.

Para atuação na Educação Infantil e nas séries iniciais a licenciatura exigida é o curso de Pedagogia, cuja base de formação é a docência e esses cursos hoje são oferecidos nas modalidades presencial e à distância, garantindo a formação de muitos docentes brasileiros.

Apesar da importância da formação inicial, há uma desconexão entre a formação (inicial) no âmbito acadêmico e a que acontece no interior das escolas. Segundo Nóvoa (2009) e Gatti e Nunes (2009) na universidade a formação é predominantemente teórica, com relegação ao segundo plano dos aspectos relativos à prática. É apenas no exercício da docência, na prática, que essas aprendizagens profissionais se efetivam, pois, o futuro docente se depara com situações complexas onde tem que mobilizar conhecimentos adquiridos em disciplinas de seu curso e outros conhecimentos não disciplinares, para resolver conflitos, realizar escolhas, tomar atitudes que se converterão em experiências de aprendizagem profissional.

Gatti (2014) afirma que as Diretrizes Curriculares Nacionais para a formação de professores da Educação Básica (Resolução CNE/CP n01/2002) preveem uma maior movimentação no campo da prática, com indicação de práticas pedagógicas curriculares e estágio curricular supervisionado para que os futuros professores aprendam em contextos profissionais.

As instituições de ensino superior privadas, que se expandiram a partir dos anos 1980 apresentaram currículos pouco atentos à necessidade de estabelecer uma relação com a prática, enquanto que as universidades públicas têm proposto reformulação de alguns aspectos do curso, apesar de não conseguir tratar do âmago da questão (GATTI; NUNES, 2009)

Considerando que a formação inicial não consegue oferecer aos docentes todos os conhecimentos necessários para seu exercício profissional, é necessário que eles continuem estudando (formação continuada) para ressignificar suas práticas diárias e, assim, oferecerem um ensino de qualidade.

Em relação à formação continuada, desde 1990 são desenvolvidos estudos e o professor passou a ser visto como sujeito que tem sua história de vida que se vincula à sua profissão, não sendo um mero executor de modelos pré-elaborados. A formação, desse modo, passou a ser vista como uma construção ao mesmo tempo individual e coletiva. É individual por ser marcada por elementos da sua vida pessoal, mas tem seu caráter coletivo por responder às demandas sociais de seu campo profissional (NÓVOA, 1991; HUBERMAN, 1995 apud BRITO, 2010; SILVA, 2010).

Nóvoa (1991) afirma que a formação do docente deve considerar seu desenvolvimento pessoal (o que diz respeito a cada um); seu desenvolvimento profissional (profissão docente) e o desenvolvimento 
organizacional (produzido na escola). Nos momentos de formação é necessário reunir esses elementos que são característicos da docência e que compõe o profissional docente, já que "[...] mais do que um lugar de aquisição de técnicas e de conhecimentos, a formação de professores é o momento chave da socialização e da configuração profissional" (NÓVOA, 1991, p. 18).

Nessa mesma perspectiva de se pensar formação docente como espaço de construção coletiva, com o intuito de desmistificar o dito que o trabalho docente tem caráter individual, tem-se os estudos de Imbernón (2010) que salienta a importância do docente como protagonista, como aquele que tem a consciência de que todos são sujeitos na construção do trabalho e que juntos, mesmo que haja diferenças, estão construindo uma identidade profissional, tendo a subjetividade como elemento de peso na forma de pensar e construir conhecimentos.

Corroborando com as concepções acima, Tardif, Lessard e Gauthier (2001, p. 11) afirmam que a profissão docente "está baseada em ações coletivas de um grupo, cuja identidade se constrói através de interações com outros grupos, instâncias e atores diversos", sendo assim uma construção social e que necessita de um saber específico.

Segundo Cruz (2014, p.11), a formação deve ser vista "como elemento de profissionalização", e esta contemplada sob a tríade profissionalização profissionalidade e profissionalismo. Desse modo, compreende-se a profissionalização como um conjunto de ações historicamente situadas que nortearão certos "parâmetros para o exercício profissional docente", e que conduz à apreensão do fazer profissional. Já o profissionalismosãoosaspectosaderidospelosdocentes, definindo um status social, legitimando a função social que exercem. Faltando a tríade a "profissionalidade" que "retrata as formas subjetivas que os profissionais vão constituindo na relação com os processos mais externos instituintes da profissionalização".

Em suma, a tríade reflete a construção da "profissionalidade", sendo esta uma dimensão da profissionalização que reflete uma relação entre os elementos de "regulação social e os aspectos mais individuais do sujeito". Pode-se, então, perceber o quanto deve ser dada importância ao momento de formação docente por tudo o que representa e reúne. Como constata-se não se trata de apenas congregar profissionais no mesmo local, mas levar em consideração a profissionalização já instituída socialmente, situando a função social do docente e a singularidade que marca a forma "de ser e estar na profissão" (CRUZ, 2014).

Para entender um pouco mais dos elementos envolvidos no processo de formação docente, tornase pertinente dissertar sobre essa construção da singularidade inerente a cada profissional e que constitui a profissionalidade, apresentando-se alguns estudos sobre a construção do saber docente na construção do fazer pedagógico.

\section{Os saberes docentes}

Os saberes que os professores constroem são múltiplos e plurais; e diversos estudiosos se debruçaram sobre como os professores constroem suas práticas e desenvolvem esses saberes, diante do exposto será apresentado, a seguir, o que esses diferentes teóricos postulam acerca da formação docente.

\section{Os saberes docentes segundo Tardif}

Tardif (2002), disserta sobre os "saberes docentes", nos ajudando a compreender o que está em jogo quando se pensa em formação docente. Em seus estudos, Maurice Tardif situa a formação docente no contexto do estudo da profissão docente, de sua história recente e de sua situação dentro da escola e da sociedade, afirmando:

[...] o saber dos professores é o saber deles e está relacionado com a pessoa e a identidade deles, com sua experiência de vida e com sua história profissional, com as suas relações com os alunos em sala de aula e com os outros atores escolares (TARDIF, 2002, p. 35)

Como pode-se perceber o docente se constrói de diferentes saberes que dialogam e se completam, e que são provenientes das instituições de formação, da formação profissional, dos currículos e da prática cotidiana. Sendo assim, Tardif (2002), apresenta alguns tipos diferentes de saberes envolvidos na atividade docente. São eles: a) saberes da formação profissional (construídos durante os processos de formação inicial ou continuada e constituem-se em conhecimentos 
pedagógicos relacionados às técnicas e métodos de ensino); b) saberes disciplinares (pertencentes aos diferentes campos de conhecimento e são produzidos e acumulados pela sociedade ao longo da história e administrado pela comunidade científica); c) saberes curriculares (relacionados à forma como as instituições educacionais gerem os conhecimentos socialmente produzidos e que apresentam-se sob a forma de programas escolares) e ; d) saberes experienciais (são resultantes do exercício da atividade profissional dos professores e relacionados ao espaço da escola e às relações estabelecidas com alunos e colegas de profissão).

A este último saber Tardif (2002) atribui uma maior importância por concentrar não apenas o saber acumulado ao longo da formação profissional e cultural, a construção individual, mas ao que se liga ao coletivo, ao exercício da docência na troca com os pares. Então, percebe-se como o favorecimento de momentos que possibilitem a troca de saberes se faz necessário no exercício da docência.

É no exercício cotidiano da docência que os professores vivenciam situações em que Ihes são exigidas habilidades, capacidade de interpretação e improvisação (CARDOSO; DEL PINO; DORNELES, 2012). Como as situações vividas são diferentes, mas próximas, o professor pode utilizar suas melhores estratégias para solucionar problemas semelhantes, desenvolvendo um habitus específico à sua profissão.

Esses diferentes saberes vêm de diferentes fontes, mas são relacionados e mobilizados de acordo com a exigência do momento e devem ser considerados conjuntamente se se quiser compreendê-los e analisálos.

Outra questão a ser considerada é que os saberes são integrados à prática profissional por processos de socialização, seja pré-profissional (antes do ingresso na carreira) ou profissional, não sendo, assim, saberes caracterizados apenas por uma construção individual, mas fruto de sua subjetividade, mas também das interações e trocas de experiências.

Cotidianamente, os professores partilham seus saberes uns com os outros através do material didático, dos "macetes", dos modos de fazer, dos modos de organizar a sala de aula, etc. Além disso, eles também trocam informações sobre alunos. Em suma, eles dividem uns com os outros um saber prático sobre sua atuação. [...] Ainda que as atividades de partilha dos saberes não sejam consideradas como obrigação ou responsabilidade profissional pelos professores, a maior parte deles expressa a necessidade de partilhar sua experiência. As reuniões pedagógicas, assim como os congressos realizados pelas diversas associações profissionais, são mencionadas pelos professores como sendo também espaços privilegiados para trocas (TARDIF, 2002, p. 53).

Nesses processos de compartilhamento de saberes, o docente vai construindo sua prática e descobrindo sua "maneira de ensinar". Isso também implica em um investimento contínuo em sua formação e um constante repensar sobre seus saberes.

Após essa breve apresentação das ideias de Tardif (2002), serão discutidas agora, as ideias de Nóvoa (2009) sobre o processo formativo.

\section{Nóvoa e a formação docente}

Enquanto Tardif (2002) apresentou os diferentes saberes que constituem o professor, Nóvoa (2009) vem discutindo alguns elementos que devem ser considerados quando se pensa em programas de formação docente, numa perspectiva de tornar esse docente dono de sua própria prática, ao mesmo tempo em que compartilha, em seu espaço de trabalho experiências e se afirma enquanto profissional para a comunidade escolar.

De acordo com ele, há cinco disposições essenciais à definição dos professores que servem como pretexto na elaboração de propostas para a formação docente. O autor postula que deve-se instituir as práticas profissionais como lugar de reflexão e formação, abandonando-se a ideia de que a profissão docente seria definida, primordialmente, "pela capacidade de transmitir um determinado saber" (NÓVOA, 2009, p.34)

O autor apresenta essas propostas de formação, onde na proposta 1 , advoga que a formação de professores deve ser centrada na aprendizagem dos alunos e no estudo de casos concretos.

1) A formação de professores avançaria se fosse organizada, preferencialmente, em torno de situações 
concretas, de problemas escolares ou programas de ação educativa, onde os professores tivessem obstinados a encontrar soluções para os problemas;

2) A importância do conhecimento ultrapassa a teoria e a prática, refletindo também o processo histórico de sua constituição, as dúvidas, as hipóteses, etc;

3) A busca de um conhecimento pertinente exige sempre um esforço de reelaboração, de reconstrução, já que o trabalho docente não é mera transposição, mas uma transformação de saberes;

4) A importância de conceber a formação de professores em contexto de responsabilidade profissional e tendo a inovação como elemento central do processo formativo.

Em sua segunda proposta o autor fala que a formação de professores deve basear-se na aquisição de uma cultura profissional, concedendo aos professores mais experientes um papel central na formação dos mais jovens.

Nóvoa (2009) discute que os professores foram alijados do processo de formação de professores, deixando que "cientistas da educação" ou "especialistas pedagógicos" com seus conhecimentos teóricos ou metodológicos assumissem a formação docente em detrimento dos professores com seus conhecimentos práticos. Esses especialistas definem currículos da formação docente, o modo de entrada na profissão, dentre outros assuntos, influenciados por organizações internacionais. Segundo ele, "a formação de um professor encerra uma complexidade que só se obtém a partir da integração numa cultura profissional" (NÓVOA, 2009, p. 36), por isso defende a necessidade dos professores formarem professores, com a investigação sendo feita dentro da própria profissão.

Ao apresentar sua terceira proposta, o autor salienta que os programas de formação docente devem dedicar uma atenção especial às dimensões pessoais da profissão docente.

Nóvoa (2009) chama a atenção para o fato do professor ser uma pessoa, o que impossibilita a separação das suas dimensões pessoais e profissionais. É então necessário que ele faça um trabalho de autorreflexão para compreender o ensino como profissão do humano e do relacional. Essa dimensão relacional o leva a refletir sobre as relações estabelecidas com os alunos e colegas. $\mathrm{O}$ autor considera importante estimular práticas de autoformação junto aos futuros professores e nos primeiros anos de docência, de modo que construam narrativas sobre suas histórias pessoal e profissional, utilizando o registro escrito como instrumento.

A proposta de número 4 relaciona-se à valorização do trabalho coletivo, já que complexidade do trabalho escolar exige que haja a formação de equipes que desenvolvam uma competência coletiva, formando redes que integra na cultura docente modos coletivos de produção e regulação do trabalho.

Para Nóvoa (2009), a escola é o lugar da formação de professores, com espaço de compartilhamento de vivências da prática docente, bem como seu acompanhamento e reflexão sobre seu fazer pedagógico, transformando a experiência coletiva em conhecimento profissional e ligando a formação docente ao desenvolvimento de projetos educativos no interior das escolas.

"A formação de professores é essencial para consolidar parcerias no interior e no exterior do mundo profissional" (NÓVOA, 2009, p. 40). A reflexão coletiva dá sentido ao desenvolvimento profissional dos professores, desse modo é imprescindível abrir espaço para as trocas de experiências no interior das escolas.

Sua última proposta, assinala que a formação de professores deve ser marcada pelo princípio de responsabilidade social.

É importante que as escolas se comuniquem com o exterior, prestem contas sobre seu trabalho, que os professores saibam explicar seu fazer pedagógico. Dessa forma, Nóvoa (2009) chama a atenção para a necessidade de o professor saber se comunicar com o público, conquistando a sociedade para o trabalho educativo que desenvolve e adquirindo visibilidade social.

\section{Schön e o professor reflexivo}

Outro teórico que discute sobre a formação de professores é Donald Schön. Ele fundamentou seu trabalho nos estudos de Dewey (1859-1952) que atribuía importância à aprendizagem através do fazer. Desse modo, Schön (1992) defende que a epistemologia da prática se embasa nos conceitos de conhecimento na ação (conhecimentos tácitos que surgem espontânea e implicitamente na ação) e de reflexão na ação. Para o autor, a reflexão seria de 3 tipos diferentes:

a) Reflexão-na-ação implica na reflexão durante 
a ação, sem interrompê-la. É o componente inteligente que orienta a atividade humana.

b) Reflexão sobre a ação- que consiste em pensar retrospectivamente sobre a ação realizada para descobrir como o ato de conhecer-na-ação contribuiu para um resultado inesperado. Essa reflexão pode ser desencadeada sem uma explicação ou sistematização teórica.

c) Reflexão sobre a reflexão-na-ação consiste em pensar na reflexão-na-ação passada para consolidar o entendimento sobre certa situação e possibilitando a adoção de uma nova estratégia, influindo em ações futuras. É caracterizada pela intencionalidade na produção da descrição verbal da reflexão-na ação.

Esses três processos consituem-se como o pensamento prático do professor e não são independentes, eles completam-se, garantindo uma intervenção prática racional.

Com esses conceitos de conhecimento e reflexão na ação, Schön (1992) levantou a bandeira do professor como um profissional reflexivo. Diversos outros pesquisadores também defenderam que era necessário tratar os professores nessa perspectiva, como foi o caso de Alarcão (1996), Freire (2001), dentre outros.

Alarcão (1996) chama a atenção para a necessidade da formação do professor reflexivo passar de um nível de formação individual para a forma coletiva, assumindo uma postura autoformativa e de busca de autonomia e de afirmação de identidade.

Ser professor implica saber quem sou, as razões pelas quais faço o que faço e consciencializar-me do lugar que ocupo na sociedade. Numa perspectiva de promoção do estatuto da profissão docente, os professores têm de ser agentes ativos do seu próprio desenvolvimento e do funcionamento das escolas como organização ao serviço do grande projeto social que é a formação dos educandos (ALARCÃO, 1996, p. 24).

É extremamente importante esse desenvolvimento de capacidades dos professores, estimulando-os a serem agentes da promoção das aprendizagens dos alunos.

Freire (2001, p.39) também falava sobre a necessidade de os professores refletirem sobre suas próprias práticas de modo a desenvolver uma ação transformadora e "o importante é que a reflexão seja um instrumento dinamizador entre teoria e prática".

Citando os estudos de Schön (2000) em seu artigo, Ferreira $(2014$, p.29) afirma que o saber da ação na atividade profissional docente discutido por ele "não se constitui na resolução de problemas práticos a partir da aplicação de teorias e técnicas científicas". Nesse caso, se constitui do "saber - fazer". Este, ainda segundo os estudos de Schön (2000) e apresentados por Ferreira (2014, p. 29):

[...] corresponde a um conjunto de regras ou planos cultivados em nossos espíritos e que precedem a ação, a acompanha, e é nessa perspectiva que ele defende a existência do "saber em ação".

De acordo com o que já foi apresentado, fica claro que no exercício da docência não está em jogo apenas a figura do docente, mas tudo o que foi e está construído nele, e a importância de contemplar esse docente no espaço da sala de aula, pois será nesse espaço de prática que as indagações, problematizações e frustações irão emergir. São quando os seus saberes são postos em jogo. Daí o pensar formação docente como momento de agenciar esses saberes respeitando o individual e a construção coletiva.

\section{REDE MUNICIPAL DE ENSINO DE RECIFE: HISTÓRICO DE FORMAÇÕES DESTINADAS AOS PROFESSORES DOS ANOS INICIAIS}

Considerando a importância da formação continuada de professores, será apresentado um breve retrospecto sobre como a formação aparece nos documentos oficiais que regem a educação no Brasil e depois, uma explanação sobre a formação continuada na Rede de Ensino de Recife.

A Conferência Mundial de Educação para Todos, acontecida na Tailândia, em 1990, levou os países participantes a estabelecerem metas para a educação e a Lei de Diretrizes e Bases da Educação Nacional (LDB), Lei 9.394/96 foi fruto de discussões e acordos para o estabelecimento dessas metas no Brasil. Quanto à formação inicial dos professores, em seu artigo 62, a 
LDB assegura que:

A formação de docentes para atuar na educação básica far-se-á em nível superior, em curso de licenciatura, de graduação plena, em universidades e institutos superiores de educação, admitida como formação mínima para o exercício do magistério na educação infantil e nas quatro primeiras séries do ensino fundamental (BRASIL, 1996)

Ela também revela a importância da formação continuada, conforme pode-se observar no artigo 67:

Os sistemas de ensino promoverão a valorização dos profissionais da educação, assegurando-lhes, inclusive nos termos dos estatutos e dos planos de carreira do magistério público: período reservado a estudos, planejamento e avaliação, incluído na carga de trabalho (BRASIL, 1996)

Como um documento que regulamenta a educação de todo o país, as redes e sistemas de ensino precisam se pautar por suas prescrições.

A LDB previa que num prazo de 10 anos, todos os professores teriam que ter concluído uma licenciatura, então, em 2003, a Prefeitura do Recife firmou um convênio com a Universidade de Pernambuco para o oferecimento de graduação em Pedagogia para os professores que ainda não eram licenciados.

Analisando as ações de formação continuada desenvolvidas pela Rede Municipal de Ensino, Santos (2010) afirma que durante os anos de 1993-1996 a proposta de formação continuada privilegiava as articulações interinstitucionais, especificamente com - Centro de Educação da Universidade Federal de Pernambuco (UFPE), centrando-se nas discussões sobre os processos de ensino-aprendizagem e de formação docente.

No período de 1997 a 2000 não houve continuidade dessa política e a parceria com a universidade se dissolve.

A partir de 2001, houve a defesa da formação continuada do professor como algo fundamental, até mesmo pela mudança no ideário pedagógico que passou a se opor ao ensino tradicional e superar o modelo de ensino que tinha o aluno como um ser passivo frente às aprendizagens. Desse modo foi pensado na ampliação de estratégias de formação continuada e um investimento em possibilidades para a realização da formação continuada no âmbito da escola.

De 2001 até o primeiro semestre de 2005 as formações eram grandes encontros, denominados de Estudos Intensivos de Rede e objetivavam promover debates e aprofundamentos teórico-metodológicos sobre a educação e o processo de ensino e aprendizagem nos ciclos de aprendizagem (SANTOS, 2010). Esses estudos aconteciam no começo de cada semestre letivo, com carga horária entre 30 a 40 horas em forma de conferências, mesas-redondas, minicursos, oficinas pedagógicas, seminários temáticos, seminários de relatos de experiências e atividades culturais (como o Conexão 17).

Em 2001, cerca de 2.700 docentes dessa rede de ensino foram inscritos na $53^{\mathrm{a}}$ Reunião Anual da Sociedade Brasileira para o Avanço da Ciência (SBPC), acontecida em Salvador/BA. Eles puderam participar de uma semana de cursos, elegendo os que fossem de seu interesse.

Mantendo esse direcionamento, nos anos posteriores os professores puderam participar das SBPCs posteriores que aconteceram em Goiânia (2002); Recife (2003) e Cuiabá (2004). Em fevereiro de 2005 houve em Recife a SBPC Regional e a SBPC/Educação.

Esse modelo de formação por meio de encontros, congressos, seminário, segundo Fusari (2001) são importantes espaços de trocas de experiências, propostas de trabalho e produções teóricas, podendo contribuir para o enriquecimento pessoal, profissional e cultural do professor ao permitir seu acesso a um contexto mais amplo de cultura e produção de conhecimento.

No segundo semestre de 2005, a Secretaria Municipal de Educação de Recife realizou um convênio com o Centro de Estudos em Educação e Linguagem (CEEL/UFPE) destinado a cerca de 2.000 (dois mil) professores dos anos iniciais, tendo como tema "Alfabetização: Apropriação do Sistema de Escrita Alfabética” (MORAIS; ALBUQUERQUE; LEAL, 2005). A formação foi ministrada usando um modelo "cascata", que consistia em atingir "inicialmente, um número restrito de professores que, posteriormente, assumiam a tarefar de transmitir/socializar as informações obtidas com seus pares em seu ambiente de trabalho" (SANTOS, 2010, 
p.237). Segundo Santos (2001 apud SANTOS, 2010) a literatura tem enfatizado a necessidade desse modelo de formação para provocar uma mudança coletiva das práticas instaladas nas escolas, já que envolveria todo o corpo docente.

Desse modo, esses professores participaram da formação através da orientação de 240 coordenadores pedagógicos, que participavam de um curso de 40 horas com formadores da universidade (CEEL/UFPE). Os coordenadores pedagógicos, nas unidades escolares, formavam grupos de estudos com os docentes, no próprio horário de trabalho para a discussão dos temas propostos no livro-texto e os problematizavam, considerando as suas vivências profissionais. Os professores receberam o livro-texto e um guia didático com as questões a serem discutidas e com atividades a serem desenvolvidas.

Entre os anos de 2006 (segundo semestre) e 2008 (primeiro semestre) outro convênio com o CEEL/UFPE foi celebrado. O Programa Pró-Letramento era destinado aos professores do $1^{\circ}$ e $2^{\circ}$ ciclos de aprendizagem (atuais anos iniciais do ensino fundamental) e contava com a parceria do MEC, CEEL/UFPE e NPADC/UFPA), promovendo estudos sobre alfabetização, língua portuguesa e matemática. $\mathrm{O}$ modelo de formação foi também o de "cascata".

Em 2007, foi ofertado curso de História, Geografia e de Avaliação da Aprendizagem. Os dois primeiros totalizaram 30 horas, distribuídos em eixos definidos segundo levantamento realizado durante estudos intensivos de 2005. Já o de Avaliação da Aprendizado foi desenvolvido por 30 professoras tutoras (coordenadores pedagógicos e técnicos da equipe de acompanhamento) para atender à reivindicação dos professores e para que a secretaria de ensino discutisse questões orientadoras da avaliação no sistema de ciclos.

No período de 2010 e 2014 as formações eram planejadas pelas gerências da diretoria de ensino e executada por parceiros dos programas e projetos da Secretaria Municipal de Educação. Segundo Macêdo (2016), as formações nesse período não poderiam ser nomeadas como continuadas, pois não tinham regularidade temporal nem sequencial em relação aos conteúdos, sendo desarticuladas da proposta de ensino. No entanto, em 2013 e 2014 houve uma revisitação da Política de Ensino da Rede Municipal de Ensino de Recife (RMER). (MACÊDO, 2016).
Em 2015 foi elaborada uma Política de Formação para atualizar os professores para que reflitam e ressignifiquem suas práticas em virtude de avanços conceituais trazidos pelas pesquisas acadêmicas. Essa política esteve pautada no compromisso com a Lei 11.738/2008 (BRASIL, 2008), que determina que carga horária dos docentes deverá ter no máximo $2 / 3$ (dois terços) voltada para o desempenho das atividades de interação com os alunos e no mínimo 1/3 (um terço) da carga horária destinado a atividades de preparação de aulas e outras atividades extraclasse, tal como a formação continuada. Desse modo, a Rede Municipal de Ensino teve que garantir a formação continuada mensal.

Desde então, as formações continuadas são oferecidas mensalmente no espaço da Escola de Formação de Educadores do Recife, doravante EFER. Elas oportunizam a formação continuada em parceria com projetos e programas desenvolvidos e são organizadas na perspectiva das diversas modalidades e áreas do conhecimento (MACÊDO, 2016).

Os professores têm $5 \mathrm{~h} / \mathrm{a}$ de formação mensal que atende à especificidade de sua etapa/modalidade de atuação (Educação Infantil, Anos Iniciais, Anos Finais, Educação de Jovens e Adultos; Atendimento Educacional Especializado, Auxiliares do Desenvolvimento Infantil).

De 2015 a 2017 as formações foram ofertadas em módulos chamado de "Trilhas", com temáticas pré-estabelecidas e fundamentadas na Política de Ensino e com carga horária mínima de 50 horas/aula anuais. As trilhas objetivavam proporcionar um diálogo entre saberes e conhecimentos formulados ao longo da experiência do docente e em sua formação inicial, garantindo oportunidade de reflexão e ressignificação das práticas.

A formação continuada de 2018 foi estruturada a partir dos resultados da discussão e consulta aos profissionais da RMER em instrumentos de avaliação disponibilizados ao longo de 2017, bem como também foi fruto do Fórum Permanente Sobre Formação Continuada da Rede Municipal de Ensino de Recife, onde se discutiu e preencheu, por segmentos, avaliações propositivas sobre as ações da Política de Formação Continuada e da consulta aos docentes por meio de um formulário eletrônico. 


\section{PROCEDIMENTOS METODOLÓGICOS}

Neste estudo, conforme descrito anteriormente, teve-se como objetivo geral verificar os impactos da formação continuada de professores na Rede Municipal de Ensino de Recife. Os objetivos específicos foram analisar os modos de organização da formação continuada no ano de 2018, bem como verificar as repercussões das formações no espaço das salas de aula.

Para alcançar esses objetivos, na tentativa de compreender as relações entre a formação continuada e a sua repercussão no fazer docente dos professores da Rede Municipal de Ensino, optou-se por realizar uma abordagem qualitativa que:

[...] se preocupa, nas ciências sociais, com um nível de realidade que não pode ser quantificado. Ou seja, ela trabalha com o universo de significados, motivos, aspirações, crenças, valores e atitudes, o que corresponde a um espaço mais profundo das relações, dos processos e dos fenômenos que não podem ser reduzidos à operacionalização de variáveis (MINAYO, 2001, p. 22).

A partir dessa abordagem foram delineados instrumentos de coleta de dados que foram adotados a fim de compreender melhor o fenômeno em questão e as etapas que se sucederiam para a realização do estudo.

A primeira parte consistiu em uma análise documental (dados divulgados pela Secretaria de Educação no início de 2018) que permitiu verificar qual foi o formato das formações realizadas na Escola de Formação de Professores Professor Paulo Freire, localizado na Madalena, Recife/PE, e sede das formações continuadas da referida rede de ensino.

Para verificar a repercussão do impacto das formações na prática docente, recorreu-se a avaliações feitas pelos professores ao fim das formações e de relatório de observações sobre a formação realizadas pelos formadores da Escola de Formação de Professores Professor Paulo Freire no período de março a setembro de 2018

$\mathrm{Na}$ referida escola, tem-se a divisão de alguns grupos de trabalho: 1) Grupo da Educação Infantil; 2) Grupo do Ciclo de Alfabetização; $3^{\circ}$ ) Grupo do $4^{\circ}$ e $5^{\circ}$ anos; 4) Grupo dos Anos Finais; 5) Grupo da Educação de Jovens e Adultos; 6) Grupo de Trabalho em Educação Sexual; 7) Grupo de Trabalho das Relações ÉtnicoRaciais. Para darmos conta desse objetivo, selecionouse um dos grupos de trabalho para focar nosso olhar: o grupo de professores de $4^{\circ}$ e $5^{\circ}$ ano do ensino fundamental. Esse grupo foi selecionado por ser um grupo de professores com o qual a pesquisadora vem trabalhando ao longo do ano, podendo acompanhar mais de perto as formações desses professores.

A etapa seguinte consistiu na tabulação e análise dos dados que permitiu a análise dos impactos da formação continuada nessa rede de ensino.

\section{RESULTADOS E DISCUSSÃO}

\section{Formato e temática das formações no ano letivo} de 2018

As formações de 2018 não seguiram o modelo das "Trilhas", realizadas de 2015 a 2017.

Conforme apresentou-se anteriormente, as formações continuadas oferecidas pela Rede Municipal de Ensino de Recife (RMER), em 2018, tiveram seus temas formulados após consultas a docentes e coordenadores pedagógicos durante $\mathrm{o}$ ano anterior. Também foi utilizada para balizar essa escolha os resultados de avaliações externas (para as turmas de professores de $4^{\circ}$ e $5^{\circ} \mathrm{s}$ anos e anos finais) e a temática desenvolvida junto ao Programa Nacional pela Alfabetização na Idade Certa (PNAIC) que atendeu a professores da Educação Infantil e Ciclo de Alfabetização durante todo o primeiro semestre.

Em 2018, o modelo de formação adotado foi o de estudos aprofundados. Esse tipo de estudo consiste no desdobramento de uma mesma temática ao longo do semestre, de forma que, a cada mês, apresenta-se um estudo vinculado a ela, em um movimento de retomada da discussão do encontro anterior e ampliação da discussão no encontro seguinte, acrescentando mais um elemento à discussão. A retomada acontecia também a partir da socialização, pelos docentes, das vivências de atividades sugeridas durante o encontro anterior.

Para ilustrar, há o exemplo da formação dos professores do $4^{\circ}$ e $5^{\circ}$ anos, realizada no primeiro semestre. O tema do semestre foi "Números racionais em situações do cotidiano". Sendo assim, no $1^{\circ}$ encontro, realizado em março, o estudo foi sobre "Frações- 
representações e ideias". No $2^{\circ}$ encontro, os formadores retomavam as discussões do primeiro momento, solicitavam às professoras que socializassem suas vivências em sala de aula e então, passavam a apresentar o segundo tema, que foi "Fração e porcentagem". No encontro seguinte, foi feita a revisitação à discussão passada e apresentação do tema "Fração, números decimais e porcentagem". No $4^{\circ}$ e último encontro do semestre o tema da formação foi "Números racionaissituações problema". Nesse encontro foram retomados os temas de todo o semestre, com um caráter ainda mais prático do que os vivenciados até então, pois houve um espaço reservado à resolução de problemas através de diferentes recursos didáticos e também de vivência de jogos relativos aos números racionais.

$\mathrm{Na}$ Tabela 1, apresenta-se como foi a divisão semestral das temáticas de formação no ano em curso.

Tabela 1 - Temáticas de formação continuada de professores da RMER no ano de 2018

\begin{tabular}{|c|c|}
\hline ETAPA ESCOLAR & TEMÁTICAS \\
\hline EDUCAÇÄ̈O INFANTLL (BERÇÁRIO AO GRUPO III) & $\begin{array}{l}\text { 10 SEMESTRE: A NEUROCIÉNCIA E O DESENVOLVIMENTO INFANTIL } \\
2^{\circ} \text { SEMESTRE: INFÂNCIA E LINGUAGEM }\end{array}$ \\
\hline EDUCAÇÄO INFANTLL (GRUPOS IV EV) & $\begin{array}{l}10 \text { SEMESTRE: CURRICULO E LINGUAGEM NA EDUCAÇÄO INFANTIL } \\
2^{\circ} \text { SEMESTRE: ANEUROCIÉNCIA E O DESENVOLVIMENTO INFANTLL }\end{array}$ \\
\hline ANOS INICIAIS (CIICLO DE ALFABETIZAÇÄO) & 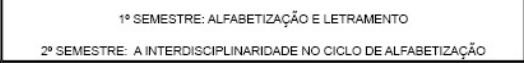 \\
\hline ANOS INICIAIS (40 E $5^{\circ}$ ANOS) & $\begin{array}{l}\text { 10 SEMESTRE: NÚMEROS RACIONAIS EM SITUAÇÓES DO COTIDIANO } \\
2 \text { SEMESTRE: LINGUAGEM EDISCURSIMDADE }\end{array}$ \\
\hline ANOS FINAIS ( $\left(0^{\circ} A O g^{\circ} A N O\right)$ & $\begin{array}{l}\text { 10 SEMESTRE: TEMÁTICAS DE ACORDO COM O COMPONENTE CURRICULAR EM } \\
\text { QUESTÄO. } \\
20 \text { SEMESTRE: TEMÁTICAS DE ACORDO COM O COMPONENTE CURRICULAR EM } \\
\text { QUESTÄO. }\end{array}$ \\
\hline EJA (FASE I) & $\begin{array}{c}10 \text { SEMESTRE: FORMAÇÃO DO SUJEITO DA ESCRITA. } \\
20 \text { SEMESTRE:AINTERDISCIPLUNARIDADE NA EJA }\end{array}$ \\
\hline EJA(FASEII) & $\begin{array}{l}\text { 10 SEMESTRE: CIDADANIA: DESAFIO E COMPROMISSO NA ESCOLA E NA SOCIEDADE } \\
22^{\circ} \text { SEMESTRE:A INTERDISCIPLINARIDADE NA EJA }\end{array}$ \\
\hline $\begin{array}{l}\text { COORDENAÇ̃̃o PEDAGÓGICA } \\
\text { (EDUCAÇÃO INFANTL) }\end{array}$ & 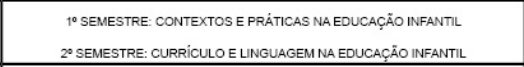 \\
\hline COORDENAÇĀO PEDAGÓGICA (ANOS INICIAIS) & $\begin{array}{l}\text { 10 SEMESTRE: ALFABETIZAÇÄO E LETRAMENTO } \\
20 \text { SEMESTRE: GESTÄO DE SALADE AULA }\end{array}$ \\
\hline COORDENAÇÃO PEDAGÓGICA (EJA) & $\begin{array}{l}1^{\circ} \text { SEMESTRE: CONTEXTOS E PRÄTICAS NA EJA } \\
2^{\circ} \text { SEMESTRE: GESTÄO DE SALADE AULA }\end{array}$ \\
\hline COORDENAÇÃO PEDAGÓGICA (ANOS FINAIS) & $1^{\circ} \mathrm{E} 2^{\circ}$ SEMESTRES: PRÁTICAS ESSENCIAIS NAFORMAC̣̃̃o DE PROFESSORES \\
\hline
\end{tabular}

Fonte: RECIFE (2018) - Formação Continuada de Professores da Rede Municipal de Ensino do Recife. Planejamento das Ações/2018

Como afirmado anteriormente, o formato das formações foi de estudos aprofundados, que prevê a problematização de conteúdos de ordem teóricopráticos, o compartilhamento de experiências. Conforme Matos et al. (2016), a formação inicial não dá conta de muitas demandas necessárias à formação docente e, dessa forma, é muito relevante a participação do docente na formação continuada:

[...] a fim de socializar experiências, solucionar os impasses da prática, compartilhar saberes, aprofundar aspectos da formação inicial, problematizar situações e dirimir-se angústias [que o circundam], principalmente ao se sentir despreparado para a atuação no ambiente de trabalho (MATOS et al., 2016, p. 48).

Compreendendo a importância desse momento onde o professorado se debruça sobre elementos teóricos e sua devida implicação na prática pedagógica, analisar-se-á agora quais seriam os impactos das formações no espaço das salas de aula.

\section{Análise da repercussão dos momentos formativos nas vivências de sala de aula}

É inegável que se espera que a formação colabore com o fazer pedagógico dos docentes, subsidiando-os para responder às demandas relacionadas ao ensino e à aprendizagem de seus alunos.

Para compreender esse impacto das formações utilizou-se algumas questões que constam na avaliação das formações, que é realizada pelos professores, ao final de cada formação, bem como as observações realizadas pelos formadores durante o período de março a setembro do ano em curso.

Em virtude do número de professores e temáticas serem extremamente grandes na Rede Municipal de Ensino de Recife, realizou-se um recorte, utilizando apenas os dados relativos ao grupo de professores de $4^{\circ}$ e $5^{\circ}$ anos, onde houve maior envolvimento dos formadores.

Vale lembrar que, no primeiro semestre, as formações foram relacionadas ao componente curricular Matemática e os professores estudaram, em movimento de retomada e aprofundamento, a temática "Números Racionais em Situações do Cotidiano".

Por ser uma rede de ensino bem numerosa, os professores são distribuídos em diferentes turmas e cada docente participam de 5h/a de formação mensal, de acordo com seu turno de trabalho.

A escola de formação atende mensalmente a cerca de 25 turmas de professores de $4^{\circ} \mathrm{s}$ e $5^{\circ} \mathrm{s}$ anos e, para fins de análise, selecionou-se uma amostra das respostas 
de apenas 5 turmas a cada mês. Reforça-se, no entanto, que no mês de maio devido à greve da categoria dos professores, contabilizou-se apenas 2 turmas.

Agora, ver-se-á a avaliação dos professores em relação a alguns aspectos da formação.

a) As atividades desenvolvidas na formação possibilitaram a articulação entre teoria e prática?

Tabela 2- Respostas de professores na Questão 1 da avaliação da formação, em percentual

\begin{tabular}{|c|c|c|c|c|}
$\begin{array}{c}\text { MÊSI } \\
\text { AVALIAÇÃo }\end{array}$ & SATISFATÓRIO & PARCIALMENTE & INSUFICIENTE & $\begin{array}{c}\text { NÃO } \\
\text { RESPONDIDO }\end{array}$ \\
\hline MARÇO & $91,4 \%$ & $8,6 \%$ & $0 \%$ & $0 \%$ \\
\hline ABRIL & $94 \%$ & $2,2 \%$ & $1,6 \%$ & $2,2 \%$ \\
\hline MAIO & $100 \%$ & $0 \%$ & $0 \%$ & $0 \%$ \\
\hline JUNHO & $100 \%$ & $0 \%$ & $0 \%$ & $0 \%$ \\
\hline AGOSTO & $88,2 \%$ & $11,8 \%$ & $0 \%$ & $0 \%$ \\
\hline
\end{tabular}

Fonte: Dados da pesquisa.

Como apresentam os dados dispostos na Tabela 2, os números referentes ao percentual de professores que considerou essa articulação teoria/prática satisfatória foi crescendo ao longo do primeiro semestre. Isso pode se justificar pelo fato de que a temática "Números racionais" ser fonte de dificuldades, no que diz respeito ao ensino, por parte dos professores, mas que as discussões de cada mês foram apresentando elementos que mostraram aos docentes ser possível ensinar de forma significativa para os alunos, trazendo informações do cotidiano e materiais bem simples para estimular a curiosidade dos alunos e fazê-los compreender os conceitos ligados a esses números racionais.

Foi afirmado anteriormente, que no mês de maio houve formação para um pequeno número de professores, devido à greve dos docentes da rede municipal de Recife, bem como a greve de caminhoneiros que se estendeu por todo o país. No entanto, esses professores que conseguiram participar da formação também se revelaram satisfeitos.

Verificou-se também que houve uma redução nos índices de satisfação quando considera a articulação entre teoria e prática no mês de agosto. Foi nesse mês que começou a formação continuada com o componente Língua Portuguesa, tratando da mediação da leitura e da construção da habilidade de construir inferências.
Mesmo sendo um índice menor que os de Matemática, verifica-se que a grande maioria dos professores mostrou que a formação tem sido adequada para auxiliá-los a pensar em sua prática e fornecer elementos para que possam aperfeiçoar seu fazer pedagógico.

Apesar da análise ter ocorrido no período de março a agosto, pode-se afirmar que, nas formações de setembro, professores que estiveram presentes à formação do mês anterior, trouxeram vários relatos dos trabalhos que fizeram a partir das discussões e trocas de experiências vivenciadas no momento de encontro com os pares na Escola de Formação de Professores Paulo Freire.

Considera-se que o planejamento das formações tem dado conta de atender à parte das necessidades dos docentes da rede. Reforça-se que é só parte dessas necessidades, pois cada professor tem suas próprias necessidades que são frutos da falta de conhecimentos didáticos anteriores e das dificuldades revelados por sua (s) turma (s) e que precisam ser refletidos e incorporados ao seu fazer docente.

b) Quanto à socialização dos saberes, houve oportunidade de compartilhar experiências?

Tabela 3 - Respostas de professores na Questão 2 da avaliação da formação, em percentual

\begin{tabular}{|c|c|c|c|c|}
\hline $\begin{array}{c}\text { MÊSI } \\
\text { AVALIAÇÃO }\end{array}$ & SATISFATÓRIO & PARCIALMENTE & INSUFICIENTE & $\begin{array}{c}\text { NÃO } \\
\text { RESPONDIDO }\end{array}$ \\
\hline MARÇO & $66 \%$ & $31 \%$ & $1,4 \%$ & $1,6 \%$ \\
\hline ABRIL & $80 \%$ & $18,4 \%$ & $1,6 \%$ & 0 \\
\hline MAIO & $95 \%$ & $5 \%$ & $0 \%$ & $0 \%$ \\
\hline JUNHO & $96,4 \%$ & $3,6 \%$ & $0 \%$ & $0 \%$ \\
\hline AGOSTO & $95,8 \%$ & $4,2 \%$ & $0 \%$ & $0 \%$ \\
\hline
\end{tabular}

Fonte: Dados da pesquisa.

Os dados que aparecem na Tabela 3 são deveras reveladores e interessantes. Assim como na tabela anterior, observa-se um crescimento contínuo entre os meses de março a junho (considerando o componente curricular Matemática).

Eles parecem sinalizar e afirmar o que se apresentou há pouco: as dificuldades dos professores no ensino de números racionais. Vejam que os professores avaliam que não tiveram muitas oportunidades de compartilhar experiências em março. Enquanto formadores, pode- 
se afirmar que em todas as formações esteve presente o espaço para compartilhamento de experiências, no entanto, no encontro inicial, os docentes pouco se colocavam por considerar que não tratavam a temática números racionais de forma suficiente, dirigindo o ensino, conforme apareceu na maioria de suas falas, apenas pelo livro didático. Nessa formação de março, os formadores pediram que buscassem, em suas escolas, os materiais que haviam para o ensino de números racionais (frações, números decimais ou porcentagem) e, no mês seguinte (abril), uma parte desses professores conseguiu trazer essas informações. Muitos afirmavam que nem sabiam da existência desses materiais na escola. Considera-se que esse foi um primeiro passo para a maior aproximação dos docentes com a temática do semestre.

É possível observar pelos números que eles se colocavam mais a cada encontro, mobilizados pela atividade que os formadores propunham para o encontro seguinte. Não eram todos que traziam devolutivas de seu trabalho após a formação, pois alegavam que havia outras demandas curriculares para o período em curso e que havia cobrança de cumprir projetos da rede de ensino em determinado prazo, não podendo, assim, operacionalizar sempre o que era proposto. Nota-se aqui, certo descompasso entre o período previsto para a formação e o período onde os conteúdos tratados deviam ser objetos de ensino para os alunos.

Em agosto, com o início do trabalho com Língua Portuguesa, pode-se observar que a maioria quase absoluta dos docentes percebeu como satisfatória o espaço que lhes era reservado para o compartilhamento de experiências. Isso pode ser explicado pelo fato da temática estar muito próxima de seu fazer docente. A temática de mediação de leitura e de ajudar o estudante a construir inferências durante a leitura é trabalhada por ele e discutida na rede de ensino há anos. Eles foram ouvidos quanto a "como se construíram enquanto leitores" e puderam relatar como costumam mediar o processo de leitura em suas turmas, revelando aí seus saberes frutos da experiência docente ou, como afirma Tardif (2002), seus saberes experienciais.

Com os dados acima, pode-se inferir que, quanto mais os docentes sabem em relação ao tema discutido na formação, mas se sentem confortáveis em relatar suas experiências e que as formações, paulatinamente vão Ihes apresentando novos elementos para repensar sua prática de forma a ampliá-la ou de consolidá-la. Pode-se verificar a importância dos diversos saberes envolvidos na atividade docente (TARDIF, 2002). Esses saberes da formação profissional, construídos nas formações inicial e continuada são importantes para que os docentes façam seus conhecimentos pedagógicos repercutir no ensino que promoverá a aprendizagem de seus alunos, mas não se pode esquecer o papel dos saberes disciplinares, curriculares, que proporcionam ao docente a segurança para o processo de ensino, sabendo o que, de fato, ensinar.

\section{CONSIDERAÇÕES FINAIS}

Ao realizar esse estudo, a intenção foi verificar os impactos da formação continuada de professores na Rede Municipal de Ensino de Recife, analisando o modo de organização da formação continuada e verificando as repercussões das formações no espaço das salas de aula.

Dentro do contexto de formação ofertado pela Rede Municipal de Ensino do Recife, percebe-se que as mudanças vêm acontecendo no intuito de fazer as formações repercutirem na prática da sala de aula. Notadamente, constata-se que a Rede de Ensino do Recife, tendenciosamente, tem concentrado as formações no espaço da Escola de Formação de Professores garantindo que as mesmas ocorram no momento de aula atividade dos (as) docentes. Analisando o modo de organização da formação ofertada no corrente ano, percebeu-se que esse modelo de estudos aprofundados foi bastante interessante, pois permitiu que os professores fossem se aproximando mais, a cada encontro formativo, da temática em questão, discutindo e rediscutindo modos de ensino que podem auxiliar na promoção de aprendizagem de seus alunos.

O modelo aproximou-se da primeira proposta de Nóvoa (2009), pois as formações foram elaboradas a partir de dificuldades dos alunos da rede municipal de ensino em relação à Matemática e Língua Portuguesa e buscando a reelaboração dos saberes dos professores de forma a tentar novas formas de promover as aprendizagens.

Com a pesquisa foi possível observar as repercussões das formações nas salas de aula através dos depoimentos dos docentes. Conforme afirmado anteriormente, nem sempre os docentes puderam dar 
devolutivas sobre suas ações docentes formuladas após os encontros de formação continuada devido ao fato de que o que estava previsto na formação do primeiro semestre só estar prescrito na grade curricular para o ensino no segundo semestre, o que prejudicou as discussões sobre o fazer-na-ação (SCHÖN, 1992). No entanto, as formações no segundo semestre mostraramse bem produtivas, nesse sentido, pois os docentes sentiram-se muito à vontade para partilharem saberes experienciais a partir das formações recebidas.

Fica claro, a partir do presente trabalho, o quanto é importante concentrar a atenção no momento de formação docente, não apenas com o intuito de atender as exigências legais; mas, sobretudo compreender o quanto esse momento pode ser significante na formação profissional e na atuação docente. Essa importância, apresentada através dos estudos aqui expostos, nos faz perceber a figura do docente como alguém que se constitui como um ser cultural, social e histórico e que aprende com as trocas possibilitadas entre seus pares, que precisa se sentir protagonista na construção do seu fazer docente e que visualiza melhoras significativas no espaço sala de aula, pois, como afirma Nóvoa (1991, p. 18), a formação de professores é "o momento chave da socialização e da configuração profissional".

É preciso salientar a importância dos encontros de formação continuada e defender a garantia desses momentos para todos os docentes, em suas respectivas redes de ensino, de modo a possibilitarIhes uma afirmação e/ou ressignificação de seu fazer pedagógico com o intuito de promover a efetivação das aprendizagens dos alunos.

\section{REFERÊNCIAS}

ALARCÃO, Isabel (Org.). Formação reflexiva de professores. Estratégias de supervisão. Porto, Portugal: Porto Editora LDA, 1996.

ALVES, Thiago.; SILVA, Rejane Moreira da. Estratificação das oportunidades educacionais no Brasil: contextos e desafios para a oferta de ensino em condições de qualidade para todos. Educação e Sociedade. Campinas: Cedes, v. 34, n. 124, p. 851-879, 2013.

AZEVEDO, Janete M. A educação como política pública. São Paulo: Autores Associados, 1997.
BRASIL. Lei $n^{\circ} 9394$ de 20 de dezembro de 1996. Estabelece as diretrizes e bases da Educação Nacional. Brasília: MEC, 1996.

Lei n. 11.738, de 16 de julho de 2008. Regulamenta a alínea "e" do inciso III do caput do art. 60 do Ato das Disposições Constitucionais Transitórias, para instituir o piso salarial profissional nacional para os profissionais do magistério público da educação básica. Brasília: MEC, 2008.

BRITO, Andréa Tereza; SILVA, Shirleide Pereira da. Formação continuada de professores: tendências atuais. In: FERREIRA, Andrea Tereza Brito; CRUZ, Shirleide Pereira da Silva (Orgs.). Formação continuada de professores: reflexões sobre a prática. Recife: Editora Universitária da UFPE, 2010.

CARDOSO, Aliana Anghinoni; DEL PINO, Mauro Augusto Burkert; DORNELLES, Caroline Lacerda. Os saberes profissionais dos professores na perspectiva de Tardif e Gauhier: Contribuições para o campo de pesquisa sobre os saberes docentes no Brasil. In: IXANPED SUL, 07, 2012. Caxias do Sul. Anais eletrônicos. Caxias do Sul: Universidade de Caxias do Sul, 2012. Disponível em: $\quad$ http://www.ucs.br/etc/conferencias/index.php/ anpedsul/9anpedsul/paper/viewFile/668/556. Acesso em: 15 ago. 2018.

CRUZ, Shirleide Pereira da Silva; FERREIRA, Andrea Tereza Brito; SILVA, Auxiliadora Maria Martins (Orgs). Formação continuada de professores: programas, projetos e recursos didáticos. Recife: Ed.: Universitária da UFPE, 2014.

FERREIRA Andrea. Formação continuada de professores: reflexões sobre a prática. Recife: Ed: Universitária da UFPE, 2014.

FREIRE, Paulo. Pedagogia da Autonomia: saberes necessários à prática educativa. São Paulo: Paz e Terra, 2001.

FUSARI, José Cerchi. Formação Contínua de Educadores na Escola em outras situações. In: BRUNO, Eliane Bambini Gorgueira; ALMEIDA, Laurinda Ramalho 
de; CRISTOV, Luiza Helena da Silva. O Coordenador Pedagógico e a formação Docente. São Paulo: Edições Loyola, 2001.

GATTI, Bernardete. Formação inicial de professores para a educação básica: pesquisas e políticas educacionais. Est. Aval. Educ., São Paulo, v. 25, n. 57, p. 24-54, jan./abr. 2014. Disponível em: http://www.fcc. org.br/pesquisa/publicacoes/eae/arquivos/1899/1899. pdf. Acesso em: 10 ago. 2018

GATTI, Bernardete.; NUNES, Marina Muniz. Formação de professores para o ensino fundamental: estudo de currículos das licenciaturas em pedagogia, língua portuguesa, matemática e ciências biológicas. São Paulo: FCC/DPE, 2009.

IMBERNÓN, Francisco. Formação continuada de professores. Trad.: Juliana dos Santos Padilha. Porto Alegre RS. Artmed, 2010.

LIBANEO, José Carlos. O dualismo perverso da escola pública brasileira: escola do conhecimento para os ricos, escola do acolhimento social para os pobres. Educ. Pesqui., São Paulo, v. 38, n. 1, p. 13-28, mar. 2012. Disponível em: http://www. scielo.br/scielo.php?script=sci_arttext\&pid=s151797022012000100002\&lng=en\&nrm=iso. Acesso em: 03 dez. 2018.

MAÇAIRA, Élia de Fátima Lopes; SOUZA, Kátia Marcelina de; DEL GUERRA. Márcia Maria (Orgs.). Política de Ensino da Rede Municipal do Recife: subsídios para atualização da organização curricular. 2.ed. Recife: Secretaria de Educação, 2014. (cad.1).

MACÊDO, Sandra Serralva Rodrigues de. 2016. 137 fls. Elaboração e implementaçâo da política de formação para os servidores da educação do município do Recife/PE: considerações deste percurso. Dissertação (Mestrado) - Faculdade de Educação, Universidade Federal de Juiz de Fora, Juiz de Fora, 2016.

MATOS, Nathalia Cristina. et al. A Formação Continuada de professores da Educação Básica: uma revisão sistemática. Cadernos de Pesquisa: Pensamento Educacional. Curitiba, v. 11, n. 28, maio/ago., 2016.
Disponível em: http://www.utp.br/cadernosdepesquisa. Acesso em: 10 set. 2018.

MINAYO, Maria Cecília de Souza (Org.). Pesquisa Social. teoria, método e criatividade. 18. ed. Petrópolis: Vozes, 2001.

MORAIS, Artur Gomes; ALBUQUERQUE, Eliana Borges C. de; LEAL, Telma Ferraz (Orgs). Alfabetização: apropriação do sistema de escrita alfabética. Belo Horizonte: Autêntica, 2005.

NÓVOA, Antônio. Formação contínua de professores: realidades e perspectivas. Aveiro: Universidade de Aveiro, 1991.

Diz-me como ensinas e te direi quem és. In:

FAZENDA, Ivani (Org.) As pesquisas educacionais e a transformação do conhecimento. Campinas: Papirus, 1995.

Para uma formação de professores construída dentro da profissão. In: NÓVOA, Antônio. Professores: imagens do futuro presente. Lisboa: Educa, 2009.

PIMENTA, Selma Garrido. Formação de professores: identidade e saberes da docência. In: PIMENTA, Selma Garrido (Org.). Saberes pedagógicos e atividade docente. 3. ed. São Paulo: Cortez, 2002.

RECIFE. Formação continuada de professores da rede municipal de ensino do Recife. Planejamento das Ações/2018. Recife: Secretaria de Educação, 2018.

ROMANOWSKY, Joana Paulin. Formação inicial de professores: implicações com a educação básica. In: X EDUCERE, 11,2011. Curitiba. Anais eletrônicos. Curitiba: Pontíficia Universidade Católica do Paraná, 2011. Disponível em: http://educere.bruc.com.br/ CD2011/pdf/5198_2844.pdf. Acesso em: 15 ago. 2018.

SANTOS, Edlamar Oliveira dos. 2010. A formação continuada na rede municipal de ensino do Recife: concepções práticas de uma política em construção. Tese (Doutorado) - Centro de Educação, Universidade Federal de Pernambuco, Recife, 2010. 


\section{revista educação}

UM OLHAR SOBRE A FORMAÇÃO CONTINUADA DE PROFESSORES NA REDE MUNICIPAL DE RECIFE/PE

Mario Marcos Lopes, Luiza Maria Rodrigues Costa

SCHÖN, Donald. Formar professores como profissionais reflexivos. In: NÓVOA, António (Coord.). Os professores e sua formação. Lisboa: Dom Quixote, 1992.

SHÖN, Donald. Educando o profissional reflexivo. Porto Alegre: Artmed, 2000.

TARDIF, Maurice; LESSARD, Claude; GAUTIER, Clermont. Formação dos professores e contextos sociais. Porto: Rés, 2001.

TARDIF, Maurice. Saberes docentes e formação profissional. Petrópolis, RJ: Vozes, 2002. 